\title{
Narasi Visual Buku Pop-up Carousel tentang Edukasi Perilaku Hidup Bersih dan Sehat untuk Anak
}

\author{
Mahimma Romadhona dan Aileena Solicitor \\ Program Studi Desain Komunikasi Visual, Fakultas Arsitektur dan Desain, Universitas Pembangunan \\ Nasional "Veteran" Jawa Timur, Surabaya Indonesia \\ e-mail:mahimma.dkv@upnjatim.ac.id
}

\begin{abstract}
Abstrak-Buku pop-up sebagai media bercerita dan pembelajaran pada anak sering dijumpai. Narasi visual yang disusun untuk menuturkan cerita melalui bahasa gambar pada buku cerita anak umum dilakukan. Namun, buku pop-up dengan format carousel yang bersifat interaktif memerlukan strategi khusus dalam menyusun narasi visualnya agar isi cerita dan pesan yang ingin disampaikan dapat diterima oleh anak selaku pembaca. Tujuan penelitian ini adalah untuk menjabarkan proses kreatif penyusunan narasi visual pada buku pop-up carousel tentang edukasi Perilaku Hidup Bersih dan Sehat (PHBS) untuk anak. Metode yang dilakukan yaitu metode penelitian kualitatif. Pengumpulan data dilakukan dengan kajian pustaka, observasi langsung dan mendokumentasi obyek dalam bentuk foto. Analisis data menggunakan metode deskriptif naratif, yaitu dengan menguraikan elemen-elemen visual secara deskriptif berdasarkan kajian pustaka yang dipakai yaitu prinsip-prinsip layout. Hasil penelitian ini dapat dijadikan referensi bagi para layouter dan ilustrator buku cerita anak dalam menyusun narasi visual sebagai fungsi deskriptif dan ekspresif dari sebuah naskah cerita.
\end{abstract}

Kata Kunci- Narasi visual, buku pop-up, carousel, edukasi, PHBS

\begin{abstract}
Pop-up books as a medium for storytelling and learning in children are often encountered. Visual narratives that are structured to tell stories through the language of pictures in children's storybooks are common. However, pop-up books with an interactive carousel format require a special strategy in compiling the visual narrative so that the content of the story and the message it wants to convey can be accepted by children as readers. The purpose of this research is to describe the creative process of composing visual narratives in the pop-up carousel book about education on a Clean and Healthy Lifestyle (PHBS) for children. The method used is a qualitative research method. Data collection was carried out by literature review, direct observation, and document objects in the form of photographs. The data analysis used a descriptive narrative method, namely by describing the visual elements descriptively based on the literature review used, namely the principles of layout. The results of this study can be used as a reference for layouters and illustrators of children's storybooks in compiling visual narratives as a descriptive and expressive function of a story script.
\end{abstract}

Keywords - Visual narrative, pop-up book, carousel, education, PHBS

\section{I.PENDAHULUAN}

Buku pop-up dapat diartikan sebagai buku yang berisi catatan atau kertas bergambar tiga dimensi yang mengandung unsur interaktif pada saat dibuka seolah-olah ada sebuah benda yang muncul dari dalam buku [1]. Secara bahasa, dalam bahasa inggris arti "carousel" adalah komedi putar. Pengertian buku pop-up carousel adalah buku pop-up yang dapat dibuka hingga 360 derajat dengan posisi buku tegak berdiri sehingga buku nampak melingkar 3 dimensi. Jenis buku pop-up carousel produksi dalam negeri tidak banyak beredar di Indonesia, namun populer di luar negeri diantaranya buku terbitan Campbell Books, London. Buku pop-up carousel memiliki keunikan dibanding jenis pop-up yang lain karena formatnya yang dapat dibuka hingga 360 derajat, sehingga menyerupai panggung yang dapat dimainkan secara interaktif oleh anak. Gambar 1 menjelaskan tentang gambar tampak atas buku pop-up Carousel. Biasanya buku pop-up carousel ini dilengkapi dengan karakter bermaterial kertas (papertoys). Buku jenis ini tidak hanya menarik dari sisi cerita namun juga menarik dari sisi visual, format dan metode pendekatan kepada anak.

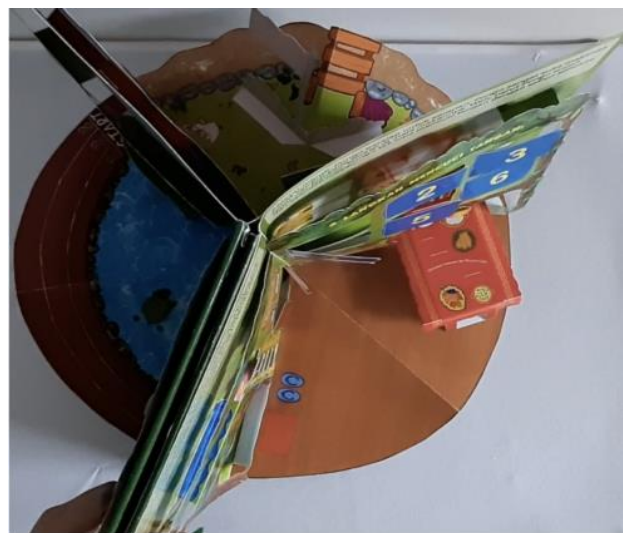

Gambar1. Tampak atas buku pop-up carousel.

Penggunaan media buku pop-up merupakan sesuatu yang dapat menarik perhatian dan dapat memancing keingintahuan untuk mengetahui sesuatu dengan cara yang Iebih menyenangkan [2]. Kefektifan bercerita menggunakan media buku Pop Up telah diriset oleh para peneliti, salah satunya adalah penelitian yang tertulis dalam jurnal berjudul Buku Pop-Up untuk Pembelajaran Bercerita Siswa Sekolah 
Dasar. Kesimpulan penelitian tersebut menyebutkan bahwa peneliti selanjutnya dapat mengembangkan produk yang lebih baik lagi dengan menggunakan lebih dari satu teknik pop-up sehingga bisa lebih menarik [3]. Oleh karena itu, buku pop-up carousel ini dapat dijadikan sebuah inovasi teknik Pop Up yang dapat dikembangkan agar buku pop-up lebih diminati.

Judul buku pop-up carousel yang dianalisa dalam penelitian ini adalah Pongo. Sebuah buku tentang edukasi Perilaku Hidup Bersih dan Sehat (PHBS) untuk anak-anak yang dikemas dalam sebuah cerita fabel.

Perilaku Hidup Bersih dan Sehat (PHBS) adalah sekumpulan perilaku yang dipraktikkan atas dasar kesadaran sebagai hasil pembelajaran, yang menjadikan seseorang keluarga, kelompok atau masyarakat mampu menolong dirinya sendiri (mandiri) di bidang kesehatan dan berperan aktif dalam mewujudkan kesehatan masyarakat [4].

Narasi visual adalah sebuah penyampaian cerita yang dilakukan melalui media dengan representasi gambar visual atau grafis, secara bergerak maupun diam. Karakteristik narasi visual adalah: 1) adanya satu cerita yang akan disampaikan, 2) elemen visual untuk meng-omunikasikan cerita tersebut, 3) adanya aktor atau partisipan untuk menjalankan cerita, 4) narasi visual yang memiliki dunia tersendiri, dan 5) narasi visual dapat diaplikasikan dalam media apapun. Narasi visual berfungsi membantu pengamat dalam memvisualisasikan cerita dalam berbagai media dimana narasi tersebut digunakan. Buku anak merupakan media dari narasi visual yang berbentuk statis karena menggunakan gambar diam untuk menyampaikan informasi [5] Narasi visual ini tak lepas dari ilsutrasi karakter yang diimplementasikan dalam sebuah cerita. Ilustrasi karakter adalah karya seni yang berfokus pada suatu karakter yang bertujuan bukan hanya untuk menentukan rupa karakternya, tetapi juga perilaku dan pembawaannya. Ketika menciptakan ilustrasi sebuah karakter, ilustrator harus mempertimbangkan kepribadian karakter tersebut [6].

Buku pop-up carousel yang diteliti ini termasuk kategori cerita bergambar (cergam) merujuk pada istilah yang dikemukakan oleh Salisbury. Istilah "cergam" atau "picture book" biasanya dipakai untuk menyebutkan bukubuku yang bercerita dengan mengutamakan ilustrasi, dengan beberapa baris teks pendukung [7]. Berbicara mengenai buku cergam anak, pastilah tak terlepas dari anak-anak sebagai target pembaca maupun (mayoritas) tokoh utama di dalam buku-buku. Kategori usia manusia yang disebut sebagai "anak" adalah umur 2-11 tahun, yang dibagi lagi secara spesifik menjadi masa kanak-kanak dini, yaitu 2-6 tahun dan masa kanak-kanak akhir, yaitu 7-11 tahun [8].

\section{II.METODE}

Metode penelitian yang digunakan adalah kualitatif. Penelitian kualitatif bersifat fleksibel dan berubah-ubah sesuai kondisi lapangan. Data yang diperoleh dalam bentuk bukan angka, tetapi dapat berupa teks, dokumen, gambar, foto, artefak, atau objek-objek lain yang diketemukan di lapangan selama penelitian dilakukan [9]. Pengumpulan data dilakukan dengan kajian pustaka dan observasi. Observasi terhadap obyek secara langsung dan mendokumentasi obyek dalam bentuk foto. Analisis data menggunakan metode deskriptif naratif, yaitu dengan menguraikan elemen-elemen visual secara deskriptif berdasarkan kajian pustaka yang dipakai.

4 prinsip layout yaitu: Sequence (hierarki), Emphasis (penekanan), Balance (keseimbangan), dan Unity (kesatuan) [10]. Prinsip layout ini digunakan untuk menganalisa elemen-elemen visual pada buku pop-up carousel "Pongo" ini sehingga dapat ditelusuri elemen pembangun narasi visualnya.

\section{III.HASIL DAN PEMBAHASAN}

Buku pop-up carousel "Pongo" ini terdiri dari 8 halaman, yaitu 2 halaman pembuka cerita dan 6 halaman inti cerita. Format pop-up carousel ini terdiri dari 3 panggung dimana masing-masing panggung menampilkan latar tempat kejadian cerita yaitu rumah, sekolah dan taman bermain. Ilustrasi mendominasi isi buku sebanyak $80 \%$ dan teks $20 \%$. Hal ini ditujukan agar anak lebih tertarik terhadap isi buku karena sesuai dengan usia anak yaitu 7-8 tahun yang termasuk kategori pembaca awal.

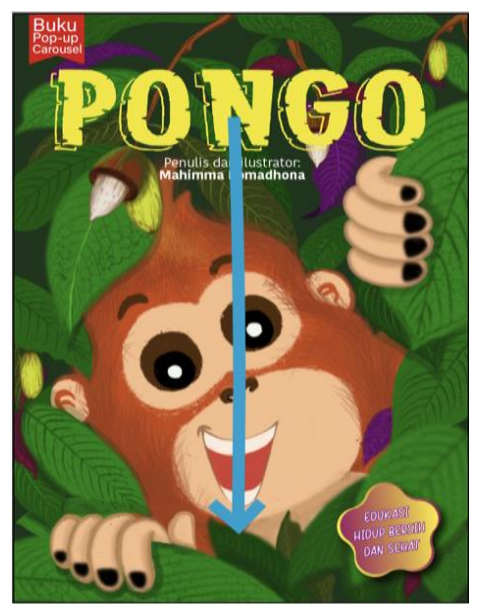

Gambar2. Sequence pada cover depan buku "Pongo".

Gambar 2 menunjukkan urutan perhatian (sequence) pada cover depan menggunakan sequence I. Hierarki ini berdasarkan alur membaca atas-bawah. Prinsip emphasis dicapai dengan pemberian ukuran font yang besar dan terletak di bagian atas tengah. Kemudian pembaca "digiring" untuk melihat ilustrasi close-up wajah karakter Pongo yang sedang menyibakkan dedaunan seolah-olah sedang mengagetkan pembaca. Ekspresi ini mengandung pesan emosional dan dapat membangkitkan rasa penasaran pembaca terhadap isi buku. Emphasis juga dicapai dengan pemberian kontras antara warna judul yaitu kuning dengan warna background hijau sehingga visibility-nya tercapai dengan baik. Prinsip unity dicapai dengan adanya kesatuan konsep isi cerita dengan ilustrasi cover. Isi cerita buku ini adalah edukasi tentang pola hidup bersih dan sehat menggunakan karakter orang utan bernama Pongo dengan latar tempat di hutan hujan tropis Kalimantan. Warna-warna ilustrasi baik ilustrasi isi buku dan cover didominasi warna hijau daun.

Halaman 1 dan 2 berisi tentang pengantar cerita yaitu pengenalan tokoh, latar tempat kejadian, dan instruksi penggunaan karakter papertoys. Adapun teks cerita pada halaman 1 dan 2 sbb: "Suatu pagi yang cerah di hutan kalimantan, hiduplah seekor Orangutan bernama Pongo. 
Pongo adalah hewan langka dan dilindungi di Indonesia. Pongo sangat suka hidup bersih dan sehat meski ia hidup di dalam hutan. Yuk, ikuti petualangan Pongo hidup bersih dan sehat saat di rumah, di sekolah dan di taman bermain bersama teman-temannya! Mainkan stikernya dan simpan ke dalam amplop sesudah bermain".

Gambar 3 menunjukkan narasi visual pada halaman 1 dan 2 dicapai dengan Sequence $\mathrm{L}$ berdasarkan alur membaca kiri-kanan. Naskah diletakkan di bagian kiri atas agar dibaca terlebih dahulu kemudian dibawah teks tampak ilustrasi Pongo sedang bergelantungan di pohon dengan ekspresi tertawa ceria dengan ukuran besar hampir mendominasi sebagian area halaman. Hal ini dimaksudkan untuk mencapai prinsip emphasis pada layout. Sisi kanan buku diseimbangkan dengan peletakan sebuah amplop besar tempat menyimpan karakter papertoys. Prinsip Unity dicapai dengan adanya relevansi antara naskah cerita dengan ilustrasi yang ditampilkan dimana ilustrasi sudah menggambarkan suasana di dalam hutan kalimantan yang lebat dengan biji dan pohon Ulin sebagai flora khas hutan hujan tropis kalimantan.

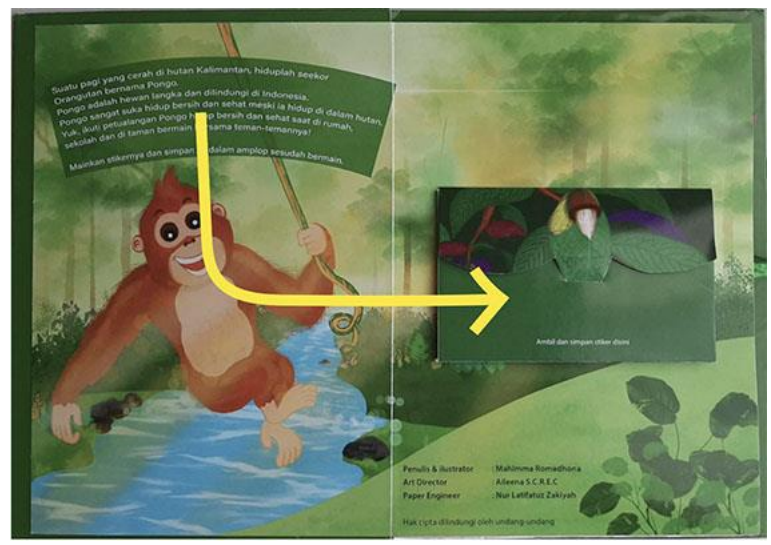

Gambar 3. Sequence dan aktivitas buku pop-up Pongo halaman 1 dan 2.

Selanjutnya, panggung 1 yaitu latar tempat rumah Pongo yang menempati halaman 3 dan 4. Adapun teks pada halaman 3: "Ini adalah rumah Pongo. Pongo sangat suka hidup bersih dan sehat. Bangun tidur Pongo segera bersiapsiap pergi ke sekolah. Saat Pongo akan mandi, Pongo sangat terkejut! Ia melihat sesuatu yang bergerak-gerak di dalam bak mandinya. Hii...ternyata itu jentik nyamuk. Wah, Pongo harus segera menguras bak mandi agar kamar mandinya bersih". Lalu teks halaman 4: "Selesai mandi, Pongo bersiap untuk sarapan. Pongo sangat suka makanan sehat seperti yang tersaji di meja makannya. Wah, perut Pongo sudah lapar nih. Namun, Pongo tak lupa mencuci tangan sebelum dan sesudah makan".

Narasi visual pada halaman 3 dicapai dengan sequence C terbalik, dan halaman 4 dicapai dengan sequence $\mathrm{L}$ berdasarkan alur membaca dan alur aktivitas karakter. Aktivitas hidup bersih dan sehat yang dilakukan karakter pada panggung ini yaitu PHBS di rumah diantaranya adalah cuci tangan memakai sabun, menggunakan air bersih, menggunakan jamban bersih dan sehat, memberantas jentik nyamuk, mengonsumsi buah dan sayur. Ilustrasi dan format pop-up dibuat sedemikian rupa menyesuaikan aktivitas PHBS tersebut. Emphasis dicapai dengan meletakkan teks "6 langkah mencuci tangan" di bagian atas diikuti dengan ilustrasi cara mencuci tangan berformat flip flap dengan ukuran angka yang besar di tiap jendelanya. Prinsip balance dicapai dengan perpaduan layout simetris dan asimetris, ukuran serta jumlah bagian pop-up dan flip-flap seimbang antara halaman 3 dan halaman 4. Prinsip unity dicapai dengan adanya kesatuan antara naskah cerita dengan ilustrasi yang dibuat. Karakter papertoys seperti aneka makanan sehat mendukung konsep hidup sehat seperti program PHBS yang dicanangkan. Kesatuan tersebut juga ditampakkan pada ilustrasi toilet dengan jentik nyamuk di dalam bak mandi dan pembaca diajak untuk "berpura-pura" menguras bak mandi menggunakan karakter gayung supaya toilet menjadi bersih. Untuk lebih jelas dapat dilihat pada Gambar 4.

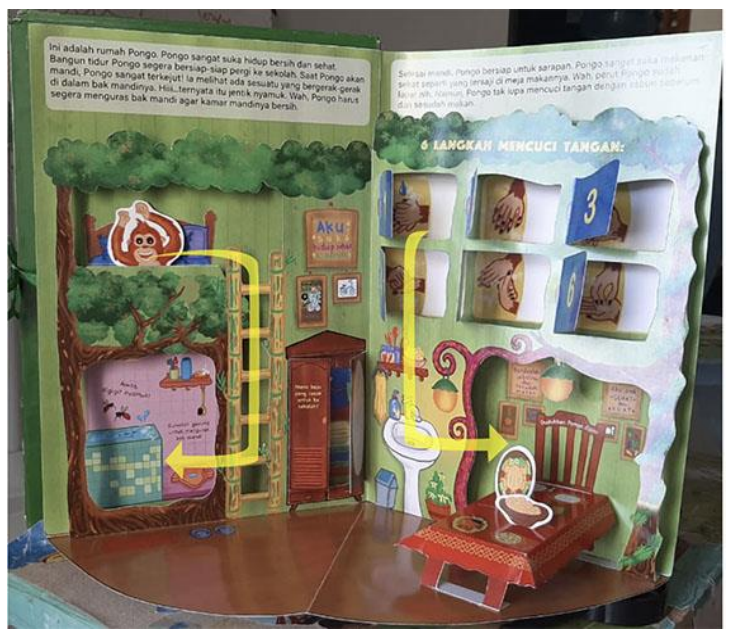

Gambar 4. Sequence dan aktivitas buku pop-up Pongo halaman 3 dan 4

Selanjutnya, panggung 2 yaitu latar tempat sekolah Pongo yang menempati halaman 5 dan 6 . Adapun naskah cerita halaman 5 yaitu: "Usai sarapan, Pongo berangkat ke sekolah. Ini adalah sekolah rimba. Sekolah Pongo asyik sekali, ada kelas di atas pohon dan ada kantin sehatnya juga lho. Bu Badak menyiapkan makanan dan minuman bergizi untuk murid-murid. Semua jajanan di kantin sehat karena makanannya tertutup, sehingga tidak ada kotoran dan lalat yang hinggap. Murid-murid juga selalu mencuci tangan sebelum dan sesudah jajan". Lalu naskah cerita halaman 6: "Tong sampah juga disediakan di sekolah. Tapi, ada si Kera yang membuang kulit pisang sembarangan nih, akibatnya si kelinci jatuh terpeleset. Aduh, kasihan sekali ya. Pongo pun segera menolongnya. Hari ini adalah jadwal kerja bakti membersihkan sekolah. Pongo dan teman-teman bergotongroyong membersihkan sekolah. Pongo merasa senang dan nyaman saat sekolahnya bersih dan sehat".

Urutan perhatian pada halaman 5 dan 6 menggunakan sequence $\mathrm{C}$ dan sequence $\mathrm{Z}$. Naskah diletakkan dibagian paling atas agar pembaca mengerti isi cerita terlebih dahulu kemudian pembaca diarahkan ke karakter pop-up yang berada dibawah teks. Aktivitas di panggung ini berdasarkan PHBS di sekolah diantaranya yaitu cuci tangan memakai sabun, menggunakan jamban bersih dan sehat, memberantas jentik nyamuk, mengonsumsi jajanan sehat, kerja bakti membersihkan lingkungan sekolah, membuang sampah pada tempatnya. Pembaca dapat membuka flip-flap dan memainkan karakter di kantin sehat dengan berpura-pura menjadi pembeli dan memesan jajanan sehat. Lalu pembaca dapat mengikuti pelajaran di sekolah pohon (sekolah rimba) 
yang berada di atas pohon, membasmi jentik nyamuk di toilet dan cuci tangan di wastafel yang disedikan. Pembaca juga diajak membersihkan lingkungan sekolah yang kotor dengan menyediakan berbagai karakter papertoys alat kebersihan seperti sapu, gunting tanaman, jaring, dll. Prinsip balance dicapai dengan perpaduan layout simetris dan asimetris. Prinsip unity dicapai dengan adanya kesatuan hubungan antara naskah cerita dengan ilustrasi yang dibuat. Ilusutrasi sudah menggambarkan nuansa sekolah rimba yang berada di tengah hutan hujan tropis yang dilengkapi dengan elemen bendera merah putih dan seragam Sekolah Dasar warna merah-putih yang menegaskan bahwa latar tempat kejadian cerita tersebut berada di Indonesia. Untuk lebih jelas dapat dilihat pada Gambar 5.
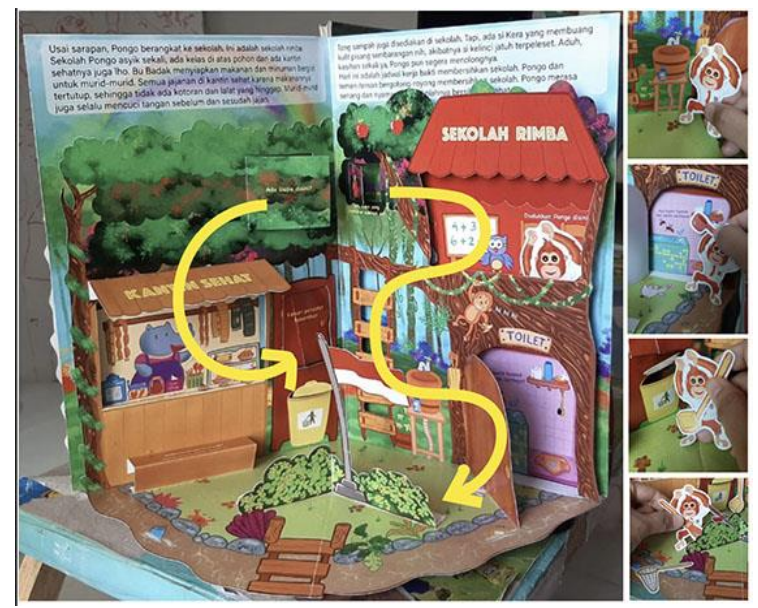

Gambar 5. Sequence dan aktivitas buku pop-up Pongo halaman 5 dan 6 .

Analisis selanjutnya adalah panggung 3 yaitu latar tempat taman rimba yang menempati halaman 7 dan 8 . Naskah cerita halaman 7 yaitu: "Sore hari sepulang sekolah, Pongo dan teman-temannya asyik bermain dan berolahraga di taman rimba. Ada yang berenang, berlari, bersepeda, dan berayun. Olahraga membuat badan sehat. Pongo sangat suka berolahraga. Olagraga kesukaannya adalah bersepeda dan berayun". Halaman 8: "Demikianlah aktivitas Pongo seharihari. Ia selalu menjaga kesehatan dengan cara hidup bersih dan sehat saat di rumah, sekolah dan sekitarnya”.

Narasi visual pada halaman 7 dan 8 dicapai dengan sequence $\mathrm{L}$ terbalik dan sequence $\mathrm{C}$. Aktivitas yang dapat dilakukan pembaca di panggung 3 ini disusun berdasarkan kegiatan olahraga pada anak, yaitu berenang, berlari, berayun dan bersepeda. Urutan perhatian pembaca yaitu dimulai dari naskah cerita yang terletak di bagian atas halaman lalu turun ke arah tempat berenang dimana karakter dapat melompat dari atas batu air terjun lalu berenang di kolam. Setelah itu, karakter Pongo dapat berlari di arena lintasan yang disediakan. Berlanjut ke sisi kanan, karakter dapat berayun dan bersepeda dengan cara meletakkan karakter pada permainan dan menggerakkannya majumundur layaknya menaiki sepeda. Prinsip balance dicapai dengan perpaduan layout simetris pada peletakan naskah dan layout asimetris pada peletakan ilustrasi permainan olahraga. Prinsip unity terlihat dari adanya hubungan antara naskah cerita dengan ilustrasi yang dibuat. Halaman ini menceritakan tentang jenis-jenis olahraga outdoor yang dapat dilakukan anak-anak. Penetrasi edukasi tentang hidup sehat dengan cara berolaharaga disampaikan dengan cara bermain peran mikro, yaitu pembaca bermain pura-pura seolah-olah menjadi karakter Pongo dalam cerita tersebut. Untuk lebih jelas dapat dilihat pada Gambar 6.

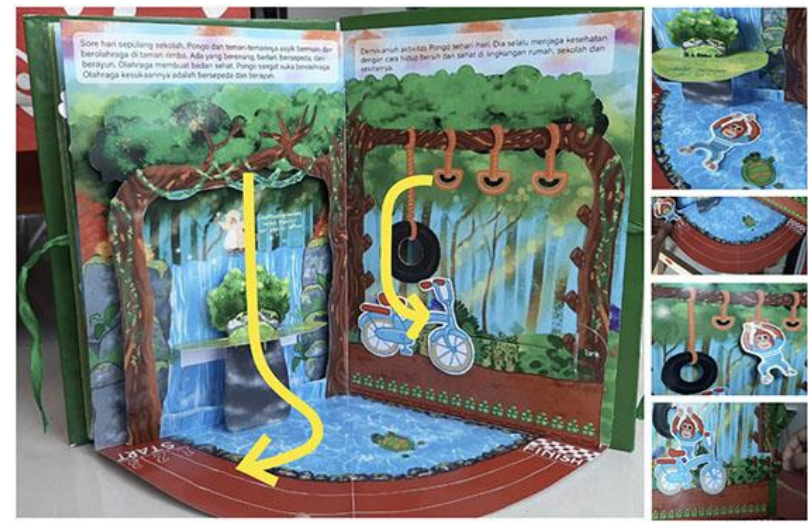

Gambar 6. Sequence dan aktivitas buku pop-up Pongo halaman 7 dan 8.

Selanjutnya pada Gambar 7 dijelaskan tentang urutan perhatian (sequence) pada cover belakang menggunakan sequence I. Hierarki ini berdasarkan alur membaca atasbawah. Prinsip emphasis dicapai dengan diawali dengan peletakan teks sinopsis cerita di bagian atas, lalu mata bergerak menuju bagian tengah dan bawah halaman. Penekanan juga dicapai dengan pemberian warna kontras pada background teks yaitu warna kuning. Warna primer tersebut nampak kontras dengan warna dasar buku yaitu hijau daun. Ilustrasi cover belakang juga dapat menggambarkan isi buku, bahwa buku ini dilengkapi dengan aneka bentuk karakter papertoys yang dapat dimainkan oleh pembaca. Hal ini menunjukkan prinsip unity telah terpenuhi.

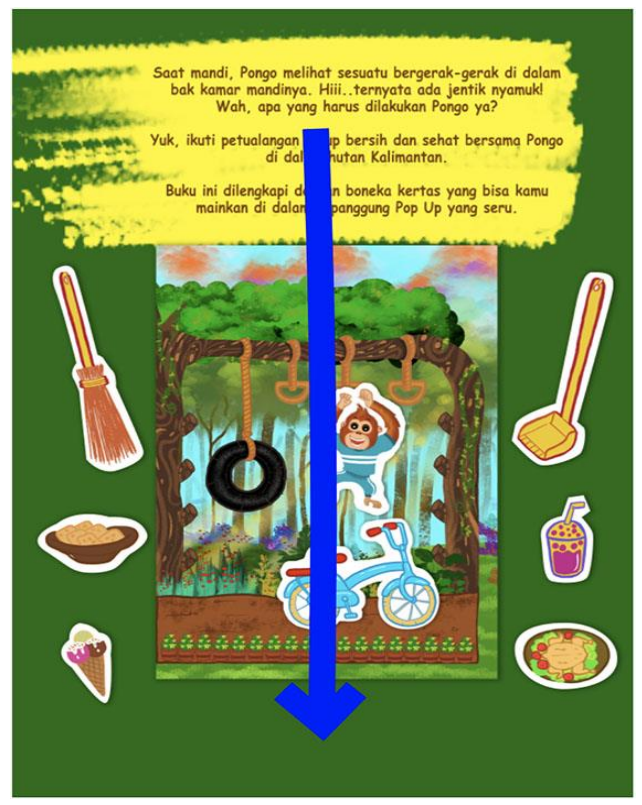

Gambar7. Sequence pada cover belakang buku "Pongo".

Selanjutnya adalah uraian tentang analisis komparator buku pop carousel sejenis yang telah terbit sebelumnya. Judul buku yang dijadikan komparator adalah "Mermaid 
Kingdom". Buku ini merupakan buku pop-up carousel terbitan Campbell Books,London. Anaslisi ini digunakan sebagai acuan dalam penyusunan narasi visual buku PONGO.

Hasil analisa mulai dari isi, ilustrasi, layout, tipografi dan cover tentang buku yang berjudul Mermaid Kingdom.

- Nama Penulis : Ag Tatkowska

- Judul Buku : Mermaid Kingdom

- Nama Ilustrator : Ag Tatkowska

- Dimensi : 24 x $30 \mathrm{~cm}$

- Halaman : 10 halaman

- Penerbit : Campbell Books, London

- Produksi Buku : Cetakan pertama 2017

Berikut adalah analisis buku sebagai Studi Komparator :

\section{Cover}

Buku ini memiliki hardcover dengan ketebalan $2 \mathrm{~mm}$. Seperti tampak pada Gambar 8, cover depan tampak ilustrasi sekumpulan mermaid di sebuah kerajaan bawah laut. Judul "Mermaid Kingdom" berada di bagian tengah atas. Ilustrasi sudah mendukung judul buku. Selain judul dan ilustrasi terdapat teks penerbit Campbell, nama penulis, keterangan "with 25 play pieces", dan "Pop-up Carousel". Sedangkan pada cover belakang, terdapat sinopsis cerita yang membuat penasaran pembaca. Disertai ilustrasi stiker mermaid dan foto buku pop-up, sehingga pembaca dapat membayangkan isi buku pop-up tersebut.

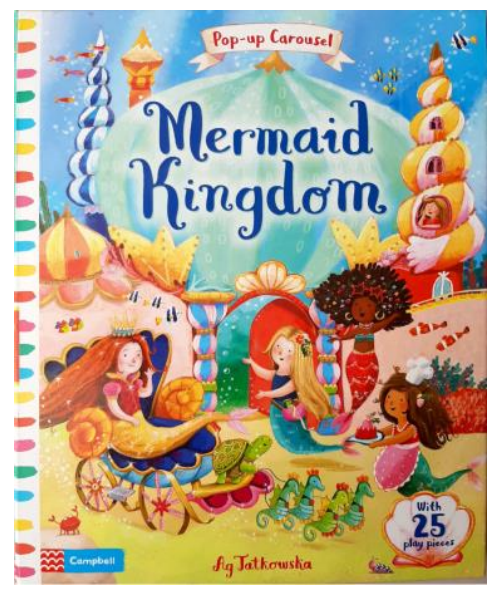

Gambar.8. Cover depan buku "Mermaid Kingdom"

Isi

Buku ini bercerita tentang 3 tokoh mermaid, yaitu Shelly si Koki, Sandy si Fashion desainer, dan Sparkle si penyanyi. Halaman awal berisi pengantar cerita dan ada sebuah amplop besar yang digunakan sebagai tempat menyimpan stiker. Halaman berikutnya bercerita tentang pengenalan karakter masing-masing tokoh. Ketiga tokoh ini ingin mempersiapkan pesta pertunjukan untuk Ratu mermaid yang ingin berkunjung. Halaman selanjutnya yaitu halaman inti buku pop-up yang berisi 3 scenes/panggung setting lokasi, yaitu scene aktivitas Shelly, Sandy, dan Sparkle. Naskah cerita terdiri dari 3-4 kalimat sederhana tiap halaman dan tiap paragraf, dimana sesuai untuk anak usia pra sekolah. Buku ini bersifat interaktif karena dilengkapi stiker dan buku berbentuk pop up dan flip flap (jendela), sehingga anak-anak dapat menggerakkan stiker-stiker pada scenes pop-up yang tersedia sekaligus memahami ceritanya. Untuk lebih jelasnya dapat dilihat pada Gambar 9.

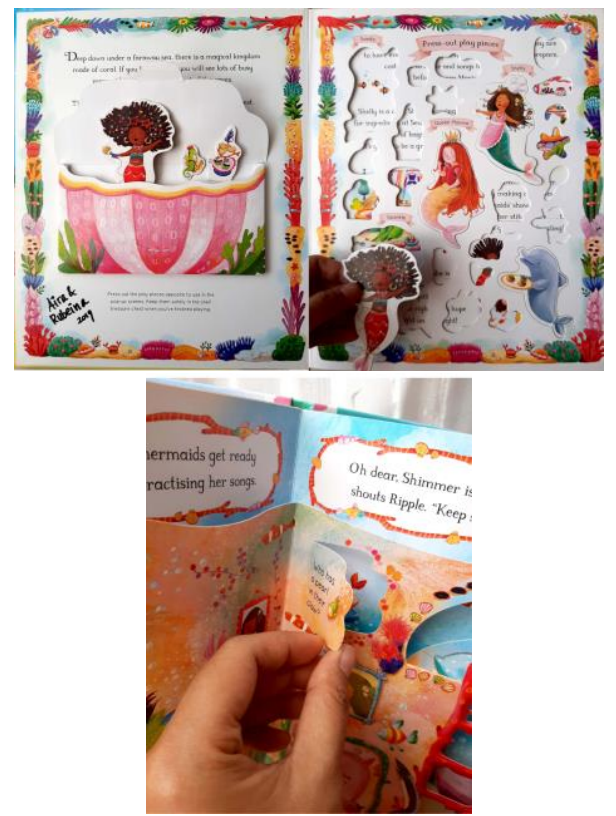

Gambar 9. Karakter papertoys dan flip flap pada buku "Mermaid Kingdom”.

\section{Ilustrasi}

Ilustrasi yang digunakan dalam buku ini menggunakan teknik digital painting dengan warna-warna tone cerah. Gambar kartun bergaya fantasi dengan karakter berbentuk rounded yang lucu. Obyek-obyek digambar dengan detil sehingga suasana dalam laut sangat terasa, seperti aneka binatang laut, kerang, batu karang, ganggang, rumput laut, dsb. Untuk lebih jelas dapat dilihat pada Gambar 10.

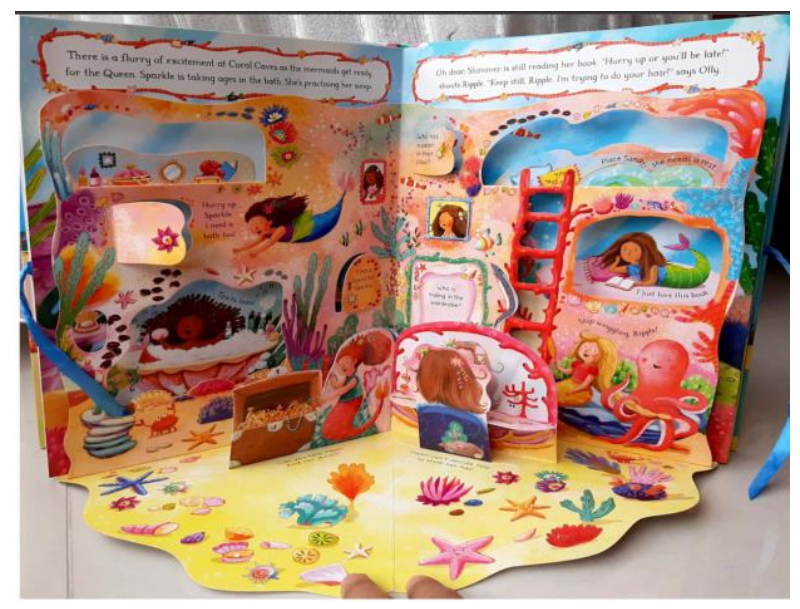

Gambar 10. Ilustrasi buku "Mermaid Kingdom”.

\section{Layout}

Layout pada buku ini menggunakan layout simetris. Penataan teks cukup seimbang antara halaman kiri dan kanan sehingga terkesan rapi meskipun menggunakan rata tengah. Ilustrasi mendominasi keseluruhan halaman sekitar $90 \%$, sisanya berupa teks. Teks pada inti cerita diletakkan di bagian atas halaman, sedangkan ilustrasi dan pop up terletak di bagian bawah teks tersebut. Teknik pop-up carousel seperti pada buku ini membuat buku harus diposisikan tegak berdiri saat dibaca atau dimainkan seperti 
tampak pada Gambar 11. Tidak seperti buku pop-up lainnya yang lying down sejajar dengan permukaan meja.

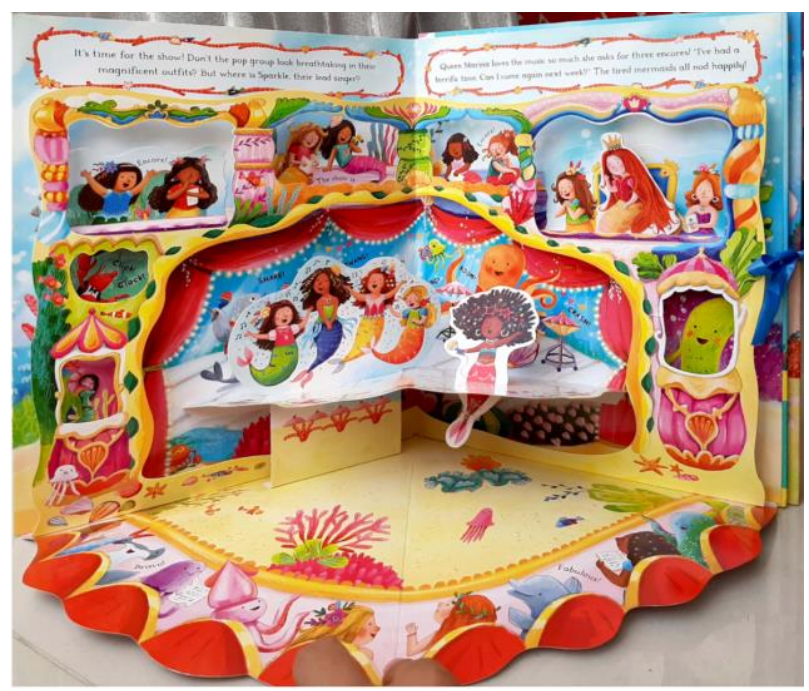

Gambar.11. Teknik pop-up carousel buku "Mermaid Kingdom"

\section{Font}

Font body teks yang digunakan adalah font berjenis serif (berkait) berwarna hitam. Ukuran font cukup besar sehingga masih terbaca jelas oleh anak-anak. Sedangkan font judul pada cover menggunakan huruf berjenis dekoratif rounded berwarna biru

tua.

\section{Ukuran}

Buku ini memiliki ukuran 24 x $30 \mathrm{~cm}$, termasuk cukup besar mengingat buku tersebut membutuhkan banyak ruang untuk memuat banyak ilustrasi dan pop-up agar dapat dibaca dan dinikmati oleh audience.

Analisis kelebihan/kekuatan buku ini dapat diuraikan sebagai berikut:

1. Buku ini berisi cerita yang menarik bagi anak-anak utamanya anak perempuan. Selain ilustrasi menarik bergaya fantasi, buku ini juga mengenalkan profesi bagi perempuan seperti koki, penyanyi dan fashion desainer.

2. Format pop-up carousel dan flip flap membuat buku ini berbeda dari buku pop-up lainnya. Buku juga dilengkapi dengan stiker-stiker yang dapat digerakkan dan dimainkan pada 3 scenes yang tersedia, sehingga anak dapat bermain sambil belajar.

3. Teks singkat sehingga anak lebih fokus pada ilustrasi dan permainan pop-up.

Analisis kekurangan/kelemahan dari buku adalah sebagai berikut:

1. Buku ini menggunakan bahasa inggris karena buku impor, sehingga sulit dibaca oleh audience lokal yang tidak mengerti bahasa inggris.
2. Harga mahal, yaitu 14,99 Euro atau sekitar 261.000 rupiah.

\section{IV.KESIMPULAN/RINGKASAN}

Narasi visual pada buku pop-up carousel yang bersifat interaktif memerlukan pemikiran mendalam dan strategi khusus agar cerita dan pesan dapat dipahami oleh pembaca. Penerapan analisa deskriptif naratif menggunakan pendekatan prinsip layout dapat menjelaskan narasi visual buku ini dengan jelas dan terukur. Uraian hasil dan pembahasan penelitian diatas bersumber dari sudut pandang ilustrator dan art director buku "Pongo". Kemungkinan perbedaan narasi visual antara sudut pandang ilustrator dan pembaca dapat saja terjadi. Hal ini dikarenakan anak memiliki daya imajinasi dan proses belajar yang berbedabeda. Untuk itu, penelitian tentang narasi visual pada buku bergambar sejenis perlu dikembangkan untuk memperkaya referensi tentang ilustrasi buku anak.

\section{UCAPAN TERIMA KASIH}

Penulis mengucapkan terima kasih kepada Lembaga Penelitian dan Pengabdian Masyarakat (LPPM) UPN "Veteran" Jawa Timur yang telah mendanai riset dasar perancangan buku pop-up carousel tentang edukasi Perilaku Hidup Bersih dan Sehat ini, sehingga keilmuan di bidang ilustrasi buku anak dapat dikembangkan.

\section{DAFTAR PUSTAKA}

[1] Hanifah, T. U. (2014). Pemanfaatan Media Pop-Up Book Berbasis Tematik untuk Meningkatkan Kecerdasan Verbal-Linguistik Anak Usia 4-5 Tahun (Studi Eksperimen di TK Negeri Pembina Bulu Temanggung). BELIA: Early Childhood Education Papers, 3(2).

[2] Asiyah, N., Fauzi, M., \& Produk, J. D. (2014). Perancangan Buku Pop Up Sebagai Media Pendidikan di Organisasi WWF Indonesia.

[3] Fadillah, R. N., \& Lestari, I. (2016). Buku Pop-Up untuk Pembelajaran Bercerita Siswa Sekolah Dasar. PERSPEKTIF Ilmu Pendidikan, 30(1), 21-26.

[4] Peraturan Kementerian Kesehatan Republik Indonesia Nomor 2269/MENKES/PERXI/2011. Pedoman Pembinaan Perilaku Hidup Bersih dan Sehat (PHBS).

[5] Indrayati, R. I., Setyawan, P., \& Saidi, A. I. (2018). Narasi Visual Kematian Pada Ilustrasi Buku Cerita Rakyat Anak Indonesia. Jurnal Budaya Nusantara, 2(1), 203-209.

[6] Pardew, Les. 2004. Beginning Illustration and Storyboarding for Games. New York: Delmar Cengage Learning.

[7] Salisbury, Martin. 2004. Illustrating children books. Singapore: Page One

[8] Hurlock, Elizabeth B. 1978. Perkembangan Anak (Jilid 1 Edisi keenam). Jakarta: Erlangga.

[9] Sarwono, Jonathan. 2007. Metodologi Penelitian Kuantitatif Dan Kualitatif, Yogjakarta. Graha Ilmu.

[10]Rustan, S. (2008). LAYOUT dasar dan penerapannya. Gramedia Pustaka Utama. 